\title{
Effects of different LDL particles on inflammatory molecules in human mesangial cells
}

\author{
E. Santini $\cdot$ R. Lupi $\cdot$ S. Baldi $\cdot$ S. Madec $\cdot$ D. Chimenti $~$ \\ E. Ferrannini • A. Solini
}

Received: 3 May 2008 / Accepted: 15 July 2008 / Published online: 28 August 2008

(C) Springer-Verlag 2008

\begin{abstract}
Aims/hypothesis Inflammation is a mechanism of glomerular damage in chronic glomerulopathies. LDL may increase the production of inflammatory cytokines in renal tissues. However, the relative role of native, oxidised and glycated LDL in promoting this process has been only partially elucidated.

Methods We tested the inflammatory and proapoptotic effects of native, oxidised and glycated LDL in human mesangial cells (HMCs) by measuring levels of IL6, CD40 and macrophage migration inhibitory factor (MIF) genes, MIF protein, release of IL6, soluble CD40, fibronectin and laminin, early and late apoptosis, and extracellular regulated kinases (ERK) 1/2 and c-Jun N-terminal kinase (JNK) activation.

Results IL6 and CD40 mRNA were dose-dependently upregulated by all three species; this was closely paralleled by their increased release. MIF mRNA was potently stimulated by modified LDL, as confirmed by immunostaining. Fibronectin and laminin release was stimulated by both oxidised and glycated, but not native, LDL. All LDL species induced some increase in late, but not early, apoptosis, and similarly activated JNK2/3 phosphorylation; in contrast, ERK1/2 phosphorylation was more strongly upregulated by oxidised than either native or glycated LDL.
\end{abstract}

E. Santini $\cdot$ S. Baldi $\cdot$ S. Madec $\cdot$ D. Chimenti $\cdot$ E. Ferrannini

A. Solini $(\bowtie)$

Department of Internal Medicine,

University of Pisa, Via Roma 67,

I-56100 Pisa, Italy

e-mail: a.solini@med.unipi.it

R. Lupi

Section of Diabetes and Metabolic Diseases,

University of Pisa, Pisa, Italy
Conclusions In HMCs, the production and release of IL6 and CD40 is stimulated by both native and modified LDL, while MIF is more strongly stimulated by oxidised LDL. Regarding the pattern of mesangial expansion, fibronectin and laminin are upregulated by oxidised and glycated LDL. Apoptosis, if modest, is induced by all species. Intracellular signalling of native and modified LDL involves JNK2/3 and, perhaps more specifically, ERK1/2. Tight control of the lipid profile may be useful in preserving kidney function in patients with metabolic alterations.

Keywords Apoptosis · Glomerulosclerosis . Human mesangial cells · Inflammation · LDL particles

Abbreviations
$\begin{array}{ll}\text { ERK } & \text { extracellular regulated kinase } \\ \text { HMC } & \text { human mesangial cell } \\ \text { JNK } & \text { c-Jun N-terminal kinase } \\ \text { MIF } & \text { macrophage migration inhibitory factor } \\ \text { sCD40L } & \text { soluble CD40 ligand } \\ \text { TBS } & \text { TRIS-buffered saline } \\ \text { TBST } & \text { TBS with Tween }\end{array}$

\section{Introduction}

Lipid-mediated renal injury is an important component of glomerulosclerosis and other chronic renal diseases; in fact, the term 'glomerular atherosclerosis' has been proposed to imply that atherosclerosis and glomerulosclerosis share common pathogenic mechanisms. Inflammation is regarded as a key mechanism underlying such damage: glomerular lipid deposition is implicated in the migration of monocytes into the mesangium, their differentiation into macrophages, and the proliferation of mesangial cells. These latter cells 
provide structural support through the production of extracellular matrix [1] and regulate glomerular blood flow and intracapillary pressure via contraction [2]; moreover, they show some properties typical of macrophages, such as phagocytosis and production of reactive oxygen species [3].

The role of oxidised LDLs in mediating tissue damage in the kidney has been extensively investigated: they mediate the production of adhesion molecules and the adhesion of monocytes to mesangial cells [4], the production of cytokines contributing to the infiltration and differentiation of monocytes [5], the induction of apoptosis [6], and the production of extracellular matrix components, all of which are fundamental pathological processes in the development and progression of glomerular diseases including focal glomerulosclerosis and diabetic nephropathy [7-9].

Macrophage migration inhibitory factor (MIF) is a cytokine that shares many activities with other proinflammatory cytokines, such as IL-1 and TNF- $\alpha[10,11]$. These cytokines mediate renal injury in experimental nephritis, including mesangial proliferative nephritis and anti-glomerular basement membrane antibody-induced glomerulonephritis [12, 13]; however, the role of MIF in chronic renal diseases such as hypertensive and diabetic nephropathy has not been clarified.

IL6 is another cytokine probably involved in mediating inflammatory damage to the kidney: IL6 is present in glomerular-resident cells and interstitial cells in the renal tissue of patients with diabetic nephropathy [14] and the cytokine is capable of inducing severe mesangial proliferation and matrix enlargement in proliferative glomerulonephritis [15].

CD40, a transmembrane protein structurally related to $\mathrm{TNF}-\alpha$, produced by monocytes, macrophages and endothelial cells, has a broader immunological function in vivo [16]. Upregulation of CD40 in mesangial cells has been observed in renal biopsies of patients with inflammatory glomerulonephritides such as lupus nephritis and $\operatorname{IgA}$ nephropathy [17].

LDL, and especially oxidised LDL, may increase the levels of several cytokines in renal vasculature and tissues, thus contributing to monocyte infiltration into the mesangial space, mesangial cell hypercellularity, and mesangial extracellular matrix deposition [18-20]. Moreover, the increased cytokine production might disturb podocyteendothelial cell communication, causing glomerular endothelial cell dysfunction and leading to microalbuminuria [21]. The relative role of native vs glycated LDL in influencing the production and release of inflammatory molecules in the kidney has been only partially elucidated. Therefore, the present study was designed to evaluate the role of different LDL particles in inducing some inflammatory and fibrogenic responses in human mesangial cells (HMCs), and to define the intracellular signalling steps potentially coupled with this effect.

\section{Methods}

Cells and reagents HMCs were obtained from normal kidney cortex of patients undergoing unilateral nephrectomy for renal cell carcinoma. We only used parts of the cortex with normal glomerular morphology, as evaluated by routine procedures. Glomeruli from the cortex of human kidney tissue were isolated by a gradual sieving procedure and plated onto gelatin-coated wells. After 15-30 days, outgrowth of mesangial cells was observed, and these were selectively collected by a cell scraper and separately expanded. The presence of endothelial or epithelial cells was excluded by antibodies against specific markers. Cells were initially cultured in RPMI 1640 medium (Gibco BRL, Eggenstein, Germany) supplemented with $10 \%$ FCS, $100 \mathrm{U} / \mathrm{ml}$ penicillin, $100 \mu \mathrm{g} / \mathrm{ml}$ streptomycin and $2 \mathrm{mmol} / \mathrm{l}$ glutamine, then shifted to DMEM (containing $5.5 \mathrm{mmol} / \mathrm{l}$ glucose) at the third passage to avoid the possibility that the modestly elevated glucose concentration of the RPMI 1640 may accelerate cell death. Subcultures were performed using trypsin/EDTA and plating cells in $75 \mathrm{~cm}^{2}$ flasks. For experimental procedures, cells between the fifth and tenth passages were kept for $24 \mathrm{~h}$ in serum-deprived medium and then stimulated with 50 and $200 \mathrm{nmol} / \mathrm{L} \mathrm{LDL}$ for $30,60,180$ and/or $360 \mathrm{~min}$. In some experiments, 10 rmol/1 U0126 (1,4-diamino-2,3-dicyano-1,4bis [2-aminophenylthio] butadiene) (Alomone, Jerusalem, Israel), a potent inhibitor of extracellular regulated kinases (ERK)1/2 phosphorylation, was used. Patients agreed to the use of cells for scientific research, and the Ethics Committee of the University of Pisa approved the protocol.

Native LDL preparation Pooled human LDL was obtained from 12 healthy, normolipidaemic volunteers. Blood was collected in tubes containing $1 \mathrm{mg} / \mathrm{ml}$ EDTA and immediately centrifuged at $1,750 \mathrm{~g}$ at $4^{\circ} \mathrm{C}$. LDL $\left(\rho=1,019-1,063 \mathrm{~kg} \mathrm{~m}^{-3}\right)$ were isolated by sequential ultracentrifugation at $177,000 \mathrm{~g}$ at $4^{\circ} \mathrm{C}$ (OPTIMA L-90 K; Beckmann, Fullerton, CA, USA) in $\mathrm{NaBr}$ solution with EDTA to avoid oxidation during isolation. Solutions were degassed and samples were kept at $4^{\circ} \mathrm{C}$ in the dark. To remove EDTA, lipoprotein fractions were gel-filtered on a Sephadex column (Econo-Pac 10DG columns; Bio-Rad, Hercules, CA, USA), and eluted in $1 \mathrm{~mol} / \mathrm{l} \mathrm{PBS}$ buffer, $\mathrm{pH}$ 7.4. The purity of LDL particles was tested by agarose gel electrophoresis, which showed a single band, i.e. lack of contamination from other lipoprotein subclasses. Stock solutions were used within 3 days.

LDL oxidation Native LDL (1 mg protein $/ \mathrm{ml}$ ) was incubated with $\mathrm{CuSO}_{4}(20 \mu \mathrm{mol} / \mathrm{l}$ final concentration $)$ in $1 \mathrm{~mol} / \mathrm{l}$ PBS pH 7.4 for $17 \mathrm{~h}$ at $37^{\circ} \mathrm{C}$. Oxidation was stopped by adding EDTA $(200 \mu \mathrm{mol} / \mathrm{l}$ final concentration). The quality of oxidation was tested by the increase in relative mobility on agarose gel, indicating an enhanced negative charge of 
oxidised LDL. We used absorbance at $234 \mathrm{~nm}$ in a Viktor3 spectrophotometer (Beckman) to evaluate conjugated diene formation in the lipid moiety. The dual wavelength $(360 \mathrm{~nm}$ excitation, $430 \mathrm{~nm}$ emission) was used as a marker of protein modification.

LDL glycation Non-enzymatic glycation of LDL was induced by incubating native LDL with $0.3 \mathrm{mmol} / 1$ EDTA at $37^{\circ} \mathrm{C}$ for 6 weeks in the dark, in the presence of $25 \mathrm{mmol} / 1$ glucose, according to the method of Brizzi et al. [22]. We used argon gas to prevent the oxidation of glycated and control LDL during the preparation, and removed unbound sugars by repeated and extensive dialysis. Control LDL incubated in the absence of glucose showed no change in mobility. Before use, LDL solutions were filtered twice by Centricon Plus-20 filters (Millipore, Bradford, MA, USA) to remove $\mathrm{Cu}^{2+}$ and/or EDTA. LDL particle concentration was adjusted to a concentration of $50 \mu \mathrm{g}$ protein $/ \mathrm{ml}$ by measuring total proteins with the bicinchoninic acid method (Sigma, St Louis, MO, USA). The amount of free lysine remaining after modification by trinitrobenzene sulphonic acid assay was slightly decreased in glycated LDL compared with native LDL $(2.49 \pm 0.04$ and $2.65 \pm 0.16 \mathrm{nmol}$ valine $/ \mu \mathrm{g}$ protein, respectively, $p=$ $0.16)$. The mean glycation degree was $25.8 \pm 1.9 \%$ compared with native LDL.

$m R N A$ expression Expression of IL6, CD40 and MIF mRNA was measured by real-time quantitative RT-PCR. Total RNA was extracted by using the RNeasy Protect Mini Kit (Qiagen, Hilden, Germany) and quantified by absorbance at $A_{260} / A_{280} \mathrm{~nm}$ (ratio $>1.65$ ) in a Perkin-Elmer spectrophotometer (Perkin-Elmer, Beaconsfield, UK). Its integrity was assessed after electrophoresis in 1.0\% (wt/vol.) agarose gels by ethidium bromide staining. The primers and probes sequences were obtained from PE Applied Biosystems (Foster City, CA, USA) (Pre-Developed TaqMan Assay Reagents Control Kits). The following assay IDs were used: IL6: Hs00174131-m1; CD40: Hs00386848-m1; MIF: Hs00236988-g1. PCR amplifications were performed in a total volume of $20 \mu \mathrm{l}$ containing $20 \mathrm{ng}$ cDNA sample, $200 \mathrm{nmol} / \mathrm{l}$ of each primer, $100 \mathrm{nmol} / \mathrm{l}$ of the corresponding probe and 12.5 $\mu$ l TaqMan Universal PCR Master Mix. For each reaction, the polymerase was activated by preincubation at $95^{\circ} \mathrm{C}$ for $10 \mathrm{~min}$. Amplification was then performed by 40 cycles of switching between $95^{\circ} \mathrm{C}$ for $15 \mathrm{~s}$ and $60^{\circ} \mathrm{C}$ for $60 \mathrm{~s}$. The quantity of each cDNA sample was normalised to the housekeeping gene for $\beta$-actin.

The LDL receptor level was also tested in these cells by PCR. Reaction mixtures were incubated for $90 \mathrm{~s}$ at $95^{\circ} \mathrm{C}$ and subjected to 30 cycles for $30 \mathrm{~s}$ at $95^{\circ} \mathrm{C}, 30 \mathrm{~s}$ at $55^{\circ} \mathrm{C}$, and $30 \mathrm{~s}$ at $72^{\circ} \mathrm{C}$. The specific primers were: $5^{\prime}$-CAATGTCT CACCAAGCTCTG and 3'-TCTGTCTCGAGGGGTA
GCTG. PCR products were subjected to electrophoresis through $2 \%$ (wt/vol.) agarose gels stained with ethidium bromide and bands visualised under ultraviolet light, then quantified by laser scanning and normalised by comparison with $\beta$-actin.

Immunocytochemistry Immunocytochemistry of MIF was performed using the streptavidin-biotin method. After incubation with different LDL fractions, cells were washed in TRIS-buffered saline ( $\mathrm{pH} 7.6$, TBS), then fixed with $4 \%$ cold formalin for $10 \mathrm{~min}$. To suppress endogenous peroxidase activity, cells were incubated for $5 \mathrm{~min}$ with $3 \% \mathrm{H}_{2} \mathrm{O}_{2}$ and, after several washings with deionised water, treated with 3\% (vol./vol.) FCS and incubated for $10 \mathrm{~min}$ at room temperature to block non-specific binding. Goat antihuman MIF polyclonal antibody (Santa Cruz Biotechnology, Santa Cruz, CA, USA) was diluted 1:300 in TBS for staining. Cells were incubated with the primary antibody for $1 \mathrm{~h}$ at room temperature and washed three times with TBST (TBS with $0.1 \%$ [vol./vol.] Tween-20) for $5 \mathrm{~min}$; the samples were then incubated for $15 \mathrm{~min}$ with biotinylated secondary antibody (Dako, Carpinteria, CA, USA) and washed three times with TBST for $5 \mathrm{~min}$. Horseradish peroxidase-labelled streptavidin from the Catalyzed Signal Amplification System (Dako) was added to the samples and incubated for $15 \mathrm{~min}$. Finally, the cells were incubated with the chromogen substrate solution, 3,3'-diaminobenzidene (Dako) for $5 \mathrm{~min}$, washed with deionised water and counterstained with Meyer's haematoxylin. The reaction was stopped by washing the sections, and chambers were mounted and observed under a light microscope. A negative control was obtained by replacing the specific antibody with non-immune serum immunoglobulins at the same concentration as the primary antibody. The degree of cytoplasmic staining was scored from 0 to 3 , corresponding to negative, weak, moderate and strong staining, respectively. The percentage of MIF-positive cells over the total mesangial cells counted $(>300)$ in five randomly selected fields was calculated and used as a labelling index of MIF levels.

Cytokine and matrix components release Supernatant fractions were harvested by centrifugation at $800 \mathrm{~g}$ for $5 \mathrm{~min}$ at $4^{\circ} \mathrm{C}$, and stored at $-70^{\circ} \mathrm{C}$. Supernatant fraction samples were thawed once and analysed for IL6, soluble CD40 ligand (sCD40L), fibronectin and laminin content in duplicate using commercially available ELISA kits with an assay reproducibility of $>95 \%$ (for IL6 and sCD40L: R\&D Systems, Minneapolis, MN, USA; for fibronectin and laminin: QuantiMatrix human ELISA kits [Chemicon, Temecula, CA, USA]).

Apoptosis Cells were incubated with 50 and $200 \mathrm{nmol} / 1$ native, oxidised and glycated LDL for $30 \mathrm{~min}$ and 3,6 and 
$24 \mathrm{~h}$. Translocation of phosphatidylserine to the outer layer of the plasma membrane (marker of early apoptosis) was detected by annexin V/propidium iodide-based flow cytometry. For this purpose, trypsinised and washed mesangial cells were stained with $10 \mu 1$ FITC-labelled annexin V (Caltag Laboratories, Burlingame, CA, USA) in $100 \mu \mathrm{l}$ annexin buffer $(10 \mathrm{mmol} / \mathrm{l}$ HEPES, $140 \mathrm{mmol} / \mathrm{l} \mathrm{NaCl}$, $5 \mathrm{mmol} / \mathrm{l} \mathrm{CaCl}_{2}, \mathrm{pH} \mathrm{7.4)}$ and incubated for $10 \mathrm{~min}$ in the dark. Then, cells were supplemented with $500 \mu \mathrm{l}$ of annexin buffer plus $10 \mu \mathrm{g} / \mathrm{ml}$ propidium iodide and analysed by recording fluorescence histograms with a FACScan flow cytometer (Becton Dickinson Labware, Bedford, MA, USA) equipped with a $488 \mathrm{~nm}$ argon ion laser. Late apoptosis was evaluated by analysing cell DNA content according to the method of Nicoletti et al. [23], based on the principle that after DNA fragmentation permeabilised cells exhibit a reduced chromatin stainability and accessibility to fluorochromes. Briefly, cells were detached from the flask, washed twice with Dulbecco's PBS (D-PBS; Sigma Aldrich, Milan, Italy) and fixed in 70\% (vol./vol.) ice-cold ethanol for $30 \mathrm{~min}$ on ice. Cells were then washed once with D-PBS, resuspended in DNA staining solution (DPBS, $20 \mu \mathrm{g} / \mathrm{ml}$ propidium iodide, $200 \mu \mathrm{g} / \mathrm{ml}$ RNase A), and incubated for $30 \mathrm{~min}$ at room temperature in the dark. Apoptotic cell nuclei containing hypodiploid DNA were expressed as a percentage of the total population. Measurements were performed using the flow cytometer indicated above.

Intracellular signalling Proteins were extracted in ice-cold NP40 lysis buffer, $1 \mathrm{mmol} / \mathrm{l}$ phenylmethylsulfonyl fluoride, $6 \mu \mathrm{g} / \mathrm{ml}$ aprotinin and $10 \mu \mathrm{g} / \mathrm{ml}$ leupeptin (Biosource, Camarillo, CA, USA) for $30 \mathrm{~min}$ with vortexing at $10 \mathrm{~min}$ intervals. The concentration of total soluble protein was quantified by the Bradford method (Bio-Rad). The extracts were employed for immunoblot analysis. Proteins $(50 \mu \mathrm{g} /$ lane) were used for electrophoresis on SDS-10\% polyacrylamide gels and transferred electrophoretically to polyvinylidene difluoride filters (Hybond-P; Amersham Biosciences, Milan, Italy). For the determination of phosphorylated ERK1/2 levels, after blocking with 5\% (wt/vol.) BSA fraction V (Sigma-Aldrich, Milan, Italy) in TBST for $1 \mathrm{~h}$, membranes were incubated overnight at $4^{\circ} \mathrm{C}$ with an anti-phospho-p44/42 ERK polyclonal antibody (Cell Signaling Technology, Danvers, MA, USA) diluted $1: 1,000$ in $5 \%$ BSA fraction V in $10 \mathrm{ml}$ TBST. Phorbol12-myristate-13-acetate, a powerful activator of ERK1/2 phosphorylation, was used at $100 \mathrm{nmol} / \mathrm{l}$ as a positive control. For the determination of phosphorylated stress-activated protein kinase (SAPK)/c-Jun N-terminal kinase (JNK) levels, after blocking the membranes were incubated overnight at $4^{\circ} \mathrm{C}$ with an anti-phospho-SAPK/JNK (Thr183/Tyr185) antibody (Cell Signaling Technology). The filters were washed and incubated for $1 \mathrm{~h}$ with Protein A-peroxidase conjugate (Calbiochem, San Diego, CA, USA) at 1:3,000 dilution. Bands were visualised by ECL chemiluminescence (Pierce Biotechnology, Rockford, IL, USA). All blots were controlled for equal loading by $\beta$-actin monoclonal antibody. The blots were quantified by densitometric scanning (Scion Image, NIH, USA) followed by data analysis.

Statistical analysis Data are presented as means $\pm \mathrm{SD}$ except where stated. Group differences were analysed by two-way ANOVA, with LDL concentration (50 and $200 \mathrm{nmol} / \mathrm{l}$ ) and type of LDL particle (native, oxidised or glycated) as the two main factors. The interaction term was always calculated, and individual group differences were tested by the post hoc Bonferroni-Dunn test. $p<0.05$ was considered statistically significant.

\section{Results}

As expected, the electrophoretic mobility of glycated LDL did not differ from that of native LDL, while mobility, conjugated dienes and fluorescence were significantly higher in oxidised LDL (Table 1), demonstrating, even in the absence of an exact quantification of the oxidation, the good quality of modified LDL.

IL6 expression was upregulated by all the three LDL classes within a very short time and time-dependently (Fig. 1a,b) and decreased within $3 \mathrm{~h}$ (data not shown). Especially at the higher concentration, the effect was progressively stronger with native, oxidised and glycated LDL. A very similar pattern, although quantitatively less pronounced, was observed for CD40 expression (Fig. 1c,d). The upregulation of mRNA was closely paralleled by an increased release of both IL6 and sCD40L (Fig. 2), confirming that message amplification was followed by an enhanced protein synthesis.

Table 1 Absorbance, fluorescence and electrophoretic mobility of native, oxidised and glycated LDL at $200 \mathrm{nmol} / \mathrm{l}$

\begin{tabular}{llll}
\hline \multirow{2}{*}{ Characteristic } & \multicolumn{3}{l}{ Ratio to native LDL (mean \pm SE, $n=3)$} \\
\cline { 2 - 4 } & Native & Oxidised & Glycated \\
\hline Absorbance & 1 & $2.0 \pm 0.2^{*}$ & $1.1 \pm 0.2$ \\
Fluorescence & 1 & $5.2 \pm 0.4^{*}$ & $1.0 \pm 0.1$ \\
Electrophoretic mobility & 1 & $1.8 \pm 0.3^{*}$ & $1.2 \pm 0.2$ \\
\hline
\end{tabular}

Absorbance was at $234 \mathrm{~nm}$, fluorescence at $360 \mathrm{~nm}$ excitation and $430 \mathrm{~nm}$ emission. Native LDL had a mean absorbance of $0.92 \mathrm{U}$, a fluorescence of $17 \mathrm{U}$ and a mobility of $6.8 \mathrm{~mm}$

${ }^{*} p<0.005$ vs native 
a

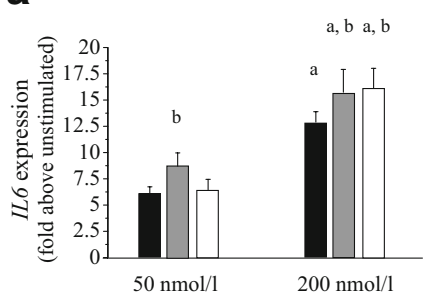

b

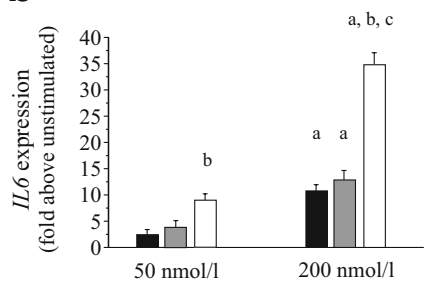

C

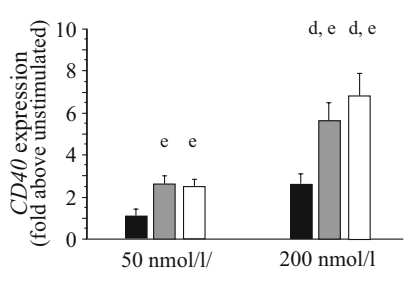

d

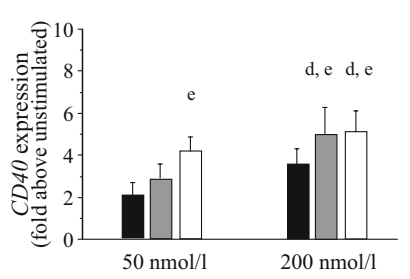

Fig. 1 IL6 and CD40 mRNA production after $30 \mathrm{~min}(\mathbf{a}, \mathbf{c})$ and $60 \mathrm{~min}(\mathbf{b}, \mathbf{d})$ of stimulation with two different concentrations of native (black bars), oxidised (dark grey bars) and glycated (white bars) LDL. Bar graphs represent means \pm SD. ${ }^{\mathrm{a}} p<0.0001$ vs $50 \mathrm{nmol} / \mathrm{l} ;{ }^{\mathrm{b}} p<$ 0.0001 vs native; ${ }^{\mathrm{c}} p<0.001$ vs oxidised; $p=0.0016$ at $30 \mathrm{~min}$ and $p=$ 0.001 at $60 \mathrm{~min}$ for the interaction between dose and LDL species by two-way ANOVA. ${ }^{\mathrm{d}} p$ between 0.003 and $0.0001 \mathrm{vs} 50 \mathrm{nmol} / \mathrm{l} ;{ }^{\mathrm{e}} p$ between 0.03 and 0.0001 vs native; $p=0.0018$ at $30 \mathrm{~min}$ for the interaction between dose and LDL species

$M I F$ expression also was dose-dependently promoted by LDL particles; unlike IL6 and CD40, however, oxidised LDL were much more potent than native or glycated LDL at both doses and times. This result was confirmed by

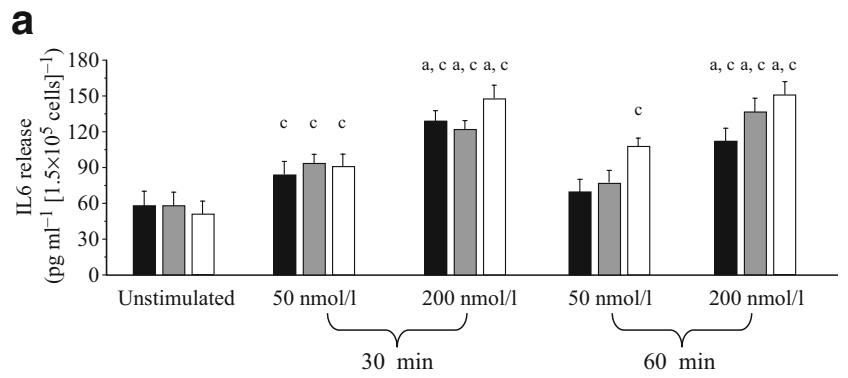

b

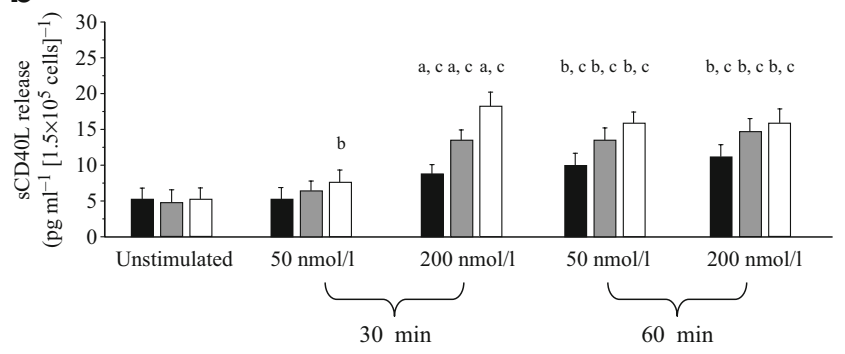

Fig. 2 IL6 (a) and SCD40L (b) release after 30 and 60 min of stimulation with two different concentrations of native (black bars), oxidised (dark grey bars) and glycated (white bars) LDL. Bar graphs represent means $\pm \mathrm{SD} .{ }^{\mathrm{a}} p<0.0001$ vs $50 \mathrm{nmol} / \mathrm{l} ;{ }^{\mathrm{b}} p<0.0001$ vs native; ${ }^{c} p<0.0001$ vs unstimulated

immunostaining: in Fig. 3 an example of weak (unstimulated), moderate (native LDL) and strong (glycated LDL and, especially, oxidised LDL) staining of MIF is reported. The labelling indices were as follows: $82 \pm 4 \%$ of unstimulated cells, $93 \pm 8 \%$ of native LDL-treated cells, $94 \pm 9 \%$ of glycated LDL-treated cells, and $98 \pm 6 \%$ of oxidised LDLtreated cells; moreover, $37 \pm 4 \%$ of unstimulated cells had a score of $1,50 \pm 8 \%$ of native LDL-treated cells had a score of 2, and $68 \pm 11 \%$ of glycated LDL-treated cells and $83 \pm$ $10 \%$ of oxidised LDL-treated cells had a score of 3 .

These proinflammatory effects were combined with a weak effect of LDL particles on LDL receptor levels, with no substantial increment of mRNA in cells treated with either native or modified LDL with respect to unstimulated cells (data not shown).

We then tested the effect of different LDL particles on the production of fibronectin and laminin, two extracellular matrix proteins whose deposition increases during chronic glomerulopathies. As shown in Fig. 4, native LDL did not exert any significant effect on fibronectin release, while oxidised and glycated LDL both increased fibronectin release, with a somewhat more rapid time-course for the former than the latter. The results for laminin production were similar (Fig. 4).

To detect any proapoptotic effect of the different LDL particles, we treated mesangial cells with native, oxidised and glycated LDL for different lengths of time. After $24 \mathrm{~h}$ of incubation (but not at earlier times, i.e. after 0.5, 3 and $6 \mathrm{~h}$, data not shown), an increase in early apoptosis was observed, which was a somewhat more marked effect with oxidised and glycated LDL than with native LDL ( $15 \pm 1$, $20 \pm 2,25 \pm 2$ and $24 \pm 2 \%$ for unstimulated, native, oxidised and glycated LDL, respectively, $p<0.001$ by ANOVA). No significant effect on late apoptosis was observed for any of the LDL particles $(1.5 \pm 0.3,0.7 \pm 0.5,0.8 \pm 0.4$ and $1.1 \pm$ $0.3 \%$, for unstimulated, native, oxidised and glycated LDL, respectively, $p=0.148$ ) (Fig. 5).

With regard to the intracellular pathway responsible for these effects, we explored whether the different LDL particles differentially activate two of the best understood mitogen-activated protein kinase subgroups: ERK1/2 (the predominant regulatory pathway involved in proliferative responses to growth factors) and JNK2/3 (an important transducing enzyme involved in gene expression, cell proliferation and apoptosis). As shown in Fig. 6, all LDL species activated both pathways; however, while JNK2/3 phosphorylation did not differ among the three, ERK1/2 phosphorylation was more strongly upregulated by oxidised than by either native or glycated LDL. The combination of LDL with U0126, an inhibitor of ERK1/2 phosphorylation, reduced by $64 \%$ the effect of oxidised LDL and by $39 \%$ the effect of glycated LDL on MIF production (Table 2). 
Fig. 3 MIF mRNA expression after $30 \mathrm{~min}$ (a) and $60 \mathrm{~min}$ (b) of stimulation with two different concentrations of native, oxidised and glycated LDL. Black bars, native LDL; dark grey bars, oxidised LDL; white bars, glycated LDL. Bar graphs represent means \pm SD. ${ }^{a} p<0.0001$ vs $50 \mathrm{nmol} / 1$; ${ }^{\mathrm{b}} p<0.0001$ vs native; ${ }^{c} p<0.001$ vs oxidised. Immunocytochemistry for MIF in untreated cells (c) and after $6 \mathrm{~h}$ of treatment with $200 \mathrm{nmol} / 1$ of native (d), oxidised (e) and glycated LDL (f) a

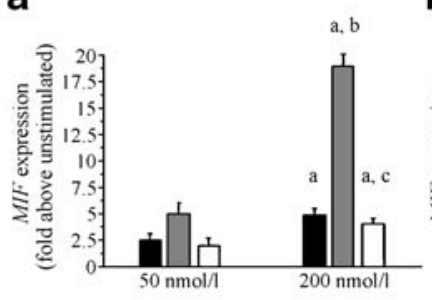

b
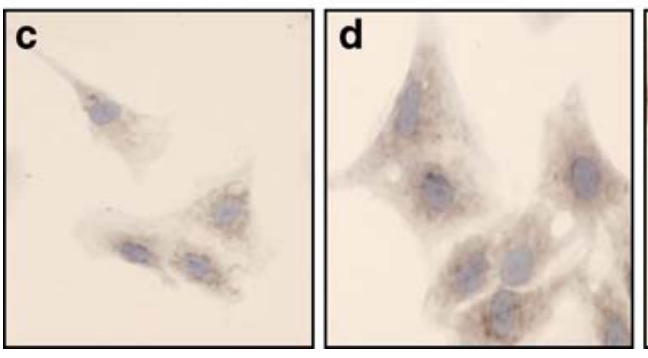
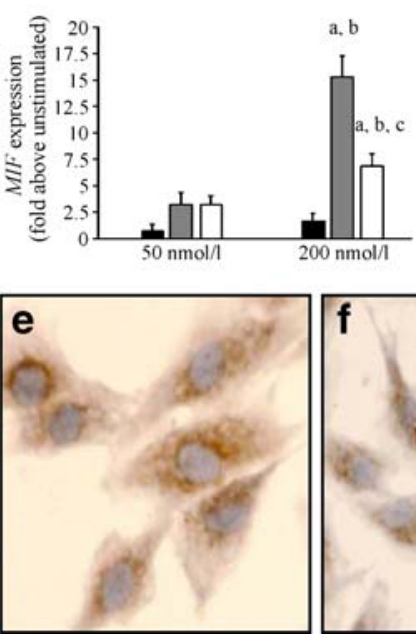

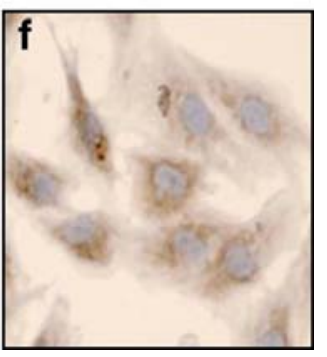

\section{Discussion}

While most circulating LDL is native, a small fraction of circulating LDL is oxidatively modified, with chemical changes similar to those induced by in vitro oxidation. Both native and oxidised LDL bind to mesangial matrix in vitro [24]; therefore, it is possible that mesangial cells in vivo are exposed to both native and oxidised LDL. Glycated LDL has been shown to induce functional changes in various cell types, including enhanced chemotactic properties in monocytes $[25,26]$, stimulated migration and proliferation of smooth muscle cells [27], and increased platelet aggrega-

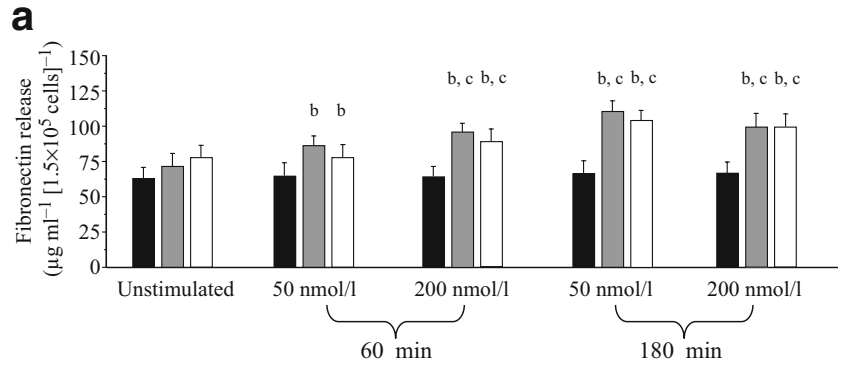

b

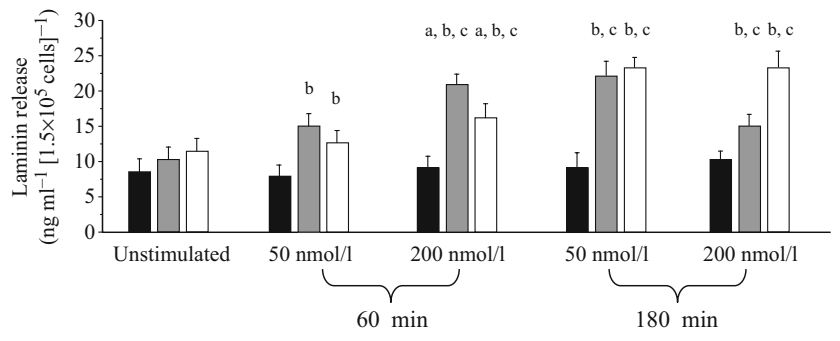

Fig. 4 Fibronectin (a) and laminin (b) release after 60 and $180 \mathrm{~min}$ of stimulation with two different concentrations of native (black bars), oxidised (dark grey bars) and glycated (white bars) LDL. Bar graphs represent means $\pm \mathrm{SD} .{ }^{\mathrm{a}} p<0.0001$ vs $50 \mathrm{nmol} / \mathrm{l} ;{ }^{\mathrm{b}} p<0.0001$ vs native; ${ }^{c} p<0.0001$ vs unstimulated tion, $\mathrm{NO}$ production and $\mathrm{Ca}^{2+}$-ATPase activity [26, 28]. Some information on the effect of native and oxidised LDL in promoting IL6 production in HMCs is available [20], while an extensive comparison of the biological activity of different LDL particles, including glycated LDL, has not been previously performed.

We show here that exposure of mesangial cells to oxidised and even native LDL in small amounts, such as might occur in vivo, can potently stimulate IL6 production. IL6 may contribute to the pathogenesis of glomerular a

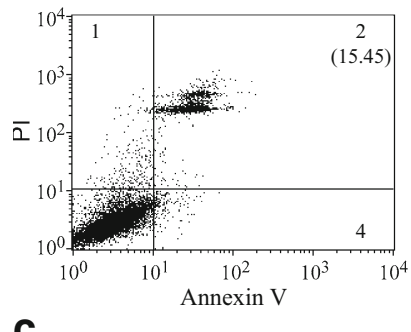

C

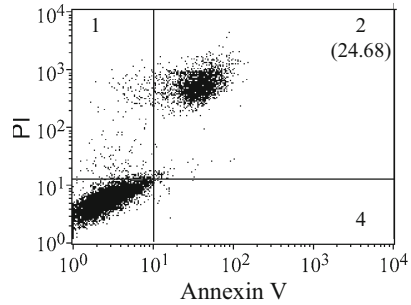

b

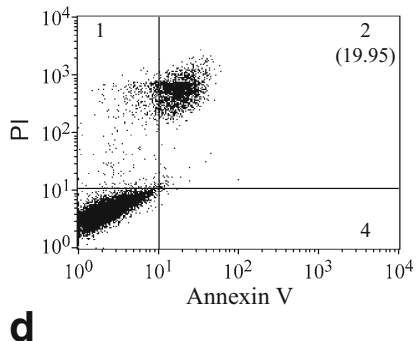

d

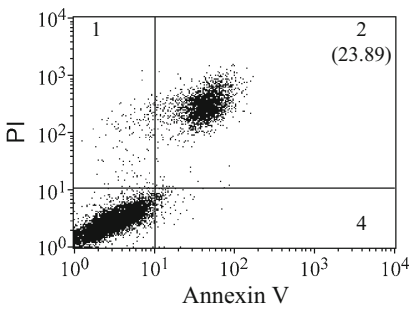

Fig. 5 Early and late apoptosis after $24 \mathrm{~h}$ incubation without stimulation (a) or stimulation with $200 \mathrm{nmol} / \mathrm{l}$ native (b), oxidised (c) and glycated (d) LDL. The graphs show the number of cells stained with annexin $\mathrm{V}$ and propidium iodide (PI). Fractions 2 and 4 indicate early and late apoptotic cells, respectively. Fraction 3 (lower left hand section in each panel) indicates viable cells. Fraction 1 indicates non-apoptotic cells. Numbers in parentheses indicate the percentage of cells in fraction 2. Representative results of three independent experiments are shown 


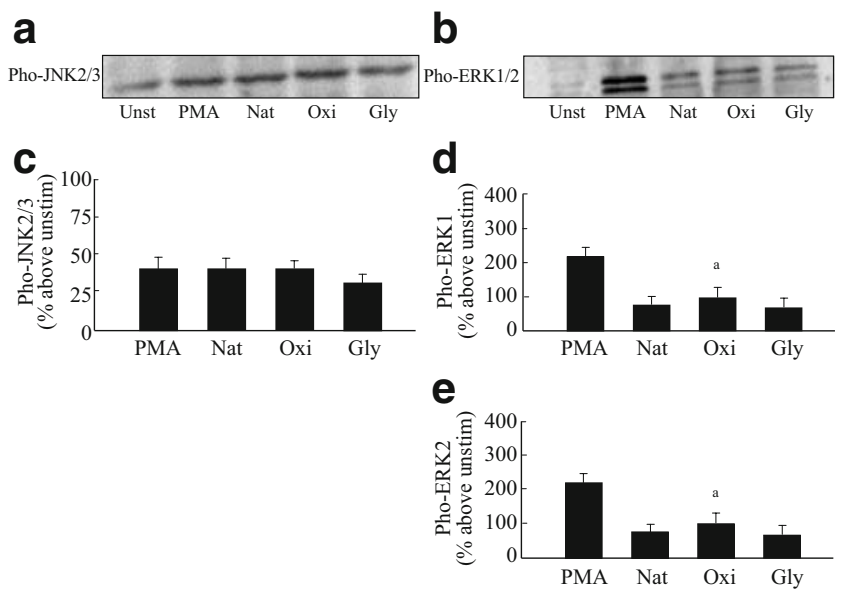

Fig. 6 Western blot analysis $(\mathbf{a}, \mathbf{b})$ and bar graphs $(\mathbf{c}-\mathbf{e})$ of the effects of $200 \mathrm{nmol} / \mathrm{l}$ native (Nat), oxidised (Oxi) and glycated (Gly) LDL on phosphorylation of JNK2/3 protein (a, c), ERK 1 protein $(\mathbf{b}, \mathbf{d})$ and ERK2 protein $(\mathbf{b}, \mathbf{e})$ in HMCs. Bar graphs represent means \pm SD of net intensity of protein bands of five independent experiments. Representative gel analyses are shown. Pho, phosphorylated; PMA, phorbol12-myristate-13-acetate; Unst, unstimulated. ${ }^{a} p<0.01$ vs native

injury either by modulation of the immune system [29] or by directly promoting glomerular damage [30]. We also found that glycated LDL particles are more potent than oxidised LDL in enhancing IL6 levels, with a more prolonged effect (Fig. 1). This may be one of the cellular mechanisms underlying the unfavourable combination of diabetes and hypercholesterolaemia as determinants of renal damage [31].

Similarly to what has been observed in activated platelets [32], all three types of LDL particles increased CD40 mRNA (CD40 is constitutively expressed on mesangial cells), with a concomitant release of sCD40L. Again, high concentrations of oxidised, and especially glycated LDL, were very active in determining this effect, whereas the effect of native LDL was slower if still significant. Because the CD40/CD40 ligand complex, induced by LDL [33], leads to an upregulation of proinflammatory cytokines, adhesion molecules and reactive oxygen species $[32,34]$, the current observations establish that LDL can

Table 2 Effect of U0126 $(10 \mu \mathrm{mol} / \mathrm{l})$ on MIF expression in HMCs after $60 \mathrm{~min}$ of treatment with native, oxidised and glycated LDL $(200 \mathrm{nmol} / \mathrm{l})$

\begin{tabular}{llcl}
\hline Conditions & \multicolumn{3}{l}{ Fold above unstimulated cells (mean $\pm \mathrm{SD}, n=3)$} \\
\cline { 2 - 4 } & Native & Oxidised & Glycated \\
\hline Without U0126 & $2.3 \pm 0.2$ & $16.1 \pm 1.2$ & $6.8 \pm 0.6$ \\
With U0126 & $2.2 \pm 0.3$ & $5.8 \pm 1.6^{* *}$ & $4.2 \pm 0.3^{*}$ \\
\hline
\end{tabular}

${ }^{*} p<0.005, * * p<0.001$, vs without directly affect the inflammatory process at the glomerular level.

In the kidney, MIF-whose role in host inflammatory and immune responses is well established [35] - is produced not only by mesangial cells and infiltrating macrophages [36] but also by glomerular epithelial and endothelial cells and by tubular cells [37]. Unlike IL6 or CD40, MIF levels were mainly influenced by oxidised LDL, as confirmed by immunocytochemistry. In agreement with previous studies [38], our findings indicate that hypercholesterolaemia can induce a classic proinflammatory response in the glomerulus, involving MIF production, immobilisation and homing of macrophages in the interstitium, release of cytokines and adhesion molecules, and, eventually, glomerular damage. Progressive diabetic nephropathy in $d b / d b$ mice was associated with increased kidney macrophages and MIF content [39]. A parallel rise in urinary levels of MIF and proteinuria has been described in patients with focal glomerulosclerosis [12]. Our finding of MIF stimulation by glycated LDL is compatible with the above pathogenetic sequence.

We find that oxidised, but not native, LDL leads to the accumulation of extracellular matrix proteins, fibronectin and laminin, a result that complements the observed enhancement of mesangial levels of these proteins [40, 41]. Interestingly, in our model this effect was similar for glycated and oxidised LDL in both amount and time-course, supporting a concerted pathogenic potential of these two species in hyperlipidaemic diabetic patients, in whom even LDL clearance via the LDL receptor is attenuated by glycation. The lack of increased levels of LDL receptors in these cells reinforces the hypothesis of an accumulation of modified LDL in the mesangial matrix. Moreover, the effects of oxidised and glycated LDL on mesangial matrix component release may both be linked with MIF-induced TGF- $\beta_{1}$ synthesis [42], a powerful promoter of fibronectin and laminin release.

In the kidney, apoptosis is one of the mechanisms of glomerular cell deletion during progressive glomerulosclerosis $[8,43]$. In our experiments, apoptosis was clearly enhanced by all three LDL species, modified LDL being somewhat more active, confirming previous observations on the proapoptotic effect of native and oxidised LDL [6] and documenting a comparable effect of glycated LDL. Even though its extent was limited, it is conceivable that the apoptotic process plays a role in determining a progressive hypocellularity during the late stages of glomerulosclerosis. The proapoptotic effect of glycated LDL, already described in endothelial cells [44], occurs in mesangial cells at a concentration $(200 \mathrm{nmol} / \mathrm{l})$ corresponding to $\sim 10 \%$ of that seen in normal human plasma, thus indicating a very high proapoptotic activity of these particles and the potential clinical relevance of the 
process. However, no foam cell formation was observed in treated cells, probably because of the relatively short time of stimulation with native or modified LDL.

Modified LDL particles have a high affinity for class B, type I scavenger receptors [45], the prime receptor mediating selective cholesteryl ester uptake from lipoprotein particles. In contrast, native LDL preferentially binds to the classic LDL receptor, and subsequent internalisation leads to uptake of cholesterol and cholesteryl esters. The fact that a high-affinity interaction of modified LDL with its receptor may lead to alteration of intracellular signalling could explain the early and long-lasting gene expression patterns induced by these species with respect to native LDL. In fact, native and modified LDL seem to induce a common signal transduction pathway in cultured HMCs; the resulting sequence of gene expression, however, occurs faster and stabilises more promptly with oxidised and glycated LDL than with native LDL [46]. Regarding these intracellular pathways, we show here that the three LDL species similarly activate the JNK mitogenactivated protein kinase pathway, which plays a major role in environmental stress and inflammatory signals, including cytokine activation and tissue remodelling. In contrast, as already described in HUVECs and vascular smooth muscle cells [47], oxidised LDLs are the most powerful in inducing ERK1/2 activation in HMCs, indicating that this pathway is the dominant one in MIF upregulation, as described in experimental models of tumoural angiogenesis [48]. In our cells, glycated LDLs were also very active, suggesting a possible direct role of high glucose, which can increase oxygen radical formation by increasing mitochondrial oxygen consumption, which in turn activates ERK1/2 phosphorylation. The relevant reduction of MIF production induced by modified LDL observed after a pharmacological inhibition of ERK1/2 supports this hypothesis.

In conclusion, in HMCs, production of IL6 and CD40 is similarly stimulated by all the LDL species, while MIF is more strongly stimulated by oxidised than by glycated LDL. Upregulation of these molecules is paralleled by an increased protein synthesis and release. With regard to the pattern of mesangial expansion, fibronectin and laminin are both significantly upregulated by oxidised and glycated LDL. Apoptosis, even though quantitatively modest, is induced by all species, native and modified, of LDL particles. These observations on the deleterious role of unmodified and modified LDL particles in both the inflammatory damage and the extracellular matrix expansion, suggest the need to explore further the complex relationship between MIF and angiogenic factors like vascular endothelial growth factor. They also support the clinical indication of a tight control of lipid profile, not only to reduce cardiovascular risk but also to preserve kidney function.
Acknowledgements The study was supported by a grant from the University of Pisa. We wish to thank Sara Burchielli for her assistance.

Duality of interest The authors declare that there is no duality of interest associated with this manuscript.

\section{References}

1. Abrass CK, Peterson CV, Raugi GJ (1988) Phenotypic expression of collagen types in mesangial matrix of diabetic and nondiabetic rats. Diabetes 37:1695-1702

2. Inokuchi S, Kimura K, Sugaya T et al (1998) Angiotensin II maintains the structure and function of glomerular mesangium via type 1a receptor. What we have learned from null mutant mice minus the angiotensin II type 1a receptor gene. Virchows Arch 433:349-357

3. Budisavljevic MN, Hodge L, Barber K et al (2003) Oxidative stress in the pathogenesis of experimental mesangial proliferative glomerulonephritis. Am J Physiol Renal Physiol 285:F1138-F1148

4. Kamanna VS, Pai R, Ha H, Kirschenbaum MA, Roh DD (1999) Oxidized low-density lipoprotein stimulates monocyte adhesion to glomerular endothelial cells. Kidney Int 55:2192-2202

5. Kamanna VS, Pai R, Roh DD, Kirschenbaum MA (1996) Oxidative modification of low-density lipoprotein enhances the murine mesangial cell cytokines associated with monocyte migration, differentiation, and proliferation. Lab Invest 74:1067-1079

6. Sharma P, Reddy K, Franki N et al (1996) Native and oxidized low density lipoproteins modulate mesangial cell apoptosis. Kidney Int 50:1604-1611

7. Galkina E, Ley K (2006) Leukocyte recruitment and vascular injury in diabetic nephropathy. J Am Soc Nephrol 17:368-377

8. Kashihara N, Sugiyama H, Makino H (2003) Implication of apoptosis in progression of renal diseases. Contrib Nephrol 139:156-172

9. Schena FP, Gesualdo L (2005) Pathogenetic mechanisms of diabetic nephropathy. J Am Soc Nephrol 16(Suppl 1):S30-S33

10. Morand EF (2005) New therapeutic target in inflammatory disease: macrophage migration inhibitory factor. Intern Med J 35:419-426

11. Donn RP, Ray W (2004) Macrophage migration inhibitory factor: molecular, cellular and genetic aspects of a key neuroendocrine molecule. J Endocrinol 182:1-9

12. Matsumoto K, Maruyama N, Maruyama T et al (2005) Elevated macrophage migration inhibitory factor (MIF) levels in the urine of patients with focal glomerular sclerosis. Clin Exp Immunol 139:338-347

13. Sasaki S, Nishihira J, Ishibashi T et al (2004) Transgene of MIF induces podocyte injury and progressive mesangial sclerosis in the mouse kidney. Kidney Int 65:469-481

14. Suzuki D, Miyazaki M, Naka R et al (1995) In situ hybridization of interleukin 6 in diabetic nephropathy. Diabetes 44:1233-1238

15. Horii Y, Iwano M, Hirata E et al (1993) Role of interleukin-6 in the progression of mesangial proliferative glomerulonephritis. Kidney Int Suppl 39:S71-S75

16. Stout RD, Suttles J (1996) The many roles of CD40 in cellmediated inflammatory responses. Immunol Today 17:487-492

17. Yellin MJ, D'Agati V, Parkinson G et al (1997) Immunohistologic analysis of renal CD40 and CD40L expression in lupus nephritis and other glomerulonephritides. Arthritis Rheum 40:124-134

18. Song CY, Kim BC, Hong HK, Lee HS (2005) Oxidized LDL activates PAI-1 transcription through autocrine activation of TGFbeta signaling in mesangial cells. Kidney Int 67:1743-1752

19. Sohn M, Tan Y, Klein RL, Jaffa AA (2005) Evidence for lowdensity lipoprotein-induced expression of connective tissue growth factor in mesangial cells. Kidney Int 67:1286-1296 
20. Massy ZA, Kih Y, Guijarro C, Kasiske BL, Keane WF, O’Donnell MP (2000) Low-density lipoprotein-induced expression of interleukin-6, a marker of human mesangial cell inflammation: effects of oxidation and modulation by lovastatin. Biochem Biophys Res Commun 267:536-540

21. Satchell SC, Tooke JE (2008) What is the mechanism of microalbuminuria in diabetes: a role for the glomerular endothelium? Diabetologia 51:714-725

22. Brizzi MF, Dentelli P, Gambino R et al (2002) STAT5 activation induced by diabetic LDL depends on LDL glycation and occurs via src kinase activity. Diabetes 51:3311-3317

23. Nicoletti I, Migliorati G, Pagliacci MC, Grignani F, Riccardi C (1991) A rapid and simple method for measuring thymocytes apoptosis by propidium iodide staining and flow cytometry. J Immunol Methods 139:271-279

24. Schlondorff D (1993) Cellular mechanisms of lipid injury in the glomerulus. Am J Kidney Dis 22:72-82

25. Millican SA, Schultz D, Bagga M, Coussons PJ, Muller K, Hunt JV (1998) Glucose-modified low density lipoprotein enhances human monocyte chemotaxis. Free Rad Res 28:533-542

26. Zoltowska M, Delvin E, Ziv E, Peretti N, Chartre M, Levy E (2004) Impact of in vivo LDL glycation on platelet aggregation and monocyte chemotaxis in Psammomys obesus. Lipids 39:81-85

27. Taguchi S, Oinuma T, Yamada T (2000) A comparative study of cultured smooth muscle cell proliferation and injury, utilizing glycated low density lipoproteins with slight oxidation, autooxidation, or extensive oxidation. J Atheroscler Thromb 3:132-137

28. Ferretti G, Rabini RA, Bacchetti T et al (2002) Glycated low density lipoproteins modify platelet properties: a compositional and functional study. J Clin Endocrinol Metab 87:2180-2184

29. Chao TK, Rifai A, Ka SM et al (2006) The endogenous immune response modulates the course of IgA-immune complex mediated nephropathy. Kidney Int 70:283-297

30. Sherianna A, Bhangal G, McDaid J et al (2007) Inhibition of $\mathrm{p} 38$ mitogen-activated protein kinase is effective in the treatment of experimental crescentic glomerulonephritis and suppresses monocyte chemoattractant protein-1 but not IL-1beta or IL-6. J Am Soc Nephrol 18:1167-1179

31. Jenkins AJ, Rowley KG, Lyons TJ, Best JD, Hill MA, Klein RL (2004) Lipoproteins and diabetic microvascular complications. Curr Pharm Des 10:3395-3418

32. Ferroni P, Santilli F, Guadagni F, Basili S, Davì G (2007) Contribution of platelet-derived CD40 ligand to inflammation, thrombosis and neoangiogenesis. Curr Med Chem 14:2170-2180

33. Schönbeck U, Gerdes N, Varo N et al (2002) Oxidized lowdensity lipoprotein augments and 3-hydroxy-3-methylglutaryl coenzyme A reductase inhibitors limit CD40 and CD40L expression in human vascular cells. Circulation 106:2888-2893

34. Steinhubl SR, Moliterno DJ (2005) The role of the platelet in the pathogenesis of atherothrombosis. Am J Cardiovasc Drugs 5:399-408
35. Larson DF, Horak K (2006) Macrophage migration inhibitory factor: controller of systemic inflammation. Crit Care 10:138

36. Tesch GH, Nikolic-Paterson DJ, Metz CN et al (1998) Rat mesangial cells express macrophage migration inhibitory factor in vitro and in vivo. J Am Soc Nephrol 9:417-424

37. Imamura K, Nishihira J, Suzuki M et al (1996) Identification and immunohistochemical localization of macrophage migration inhibitory factor in human kidney. Biochem Mol Biol Int 40:12331242

38. Hattori M, Nikolic-Paterson DJ, Miyazaki K et al (1999) Mechanisms of glomerular macrophage infiltration in lipidinduced renal injury. Kidney Int Suppl 71:S47-S50

39. Chow F, Ozols E, Nikolic-Paterson DJ, Atkins RC, Tesch GH (2004) Macrophages in mouse type 2 diabetic nephropathy: correlation with diabetic state and progressive renal injury. Kidney Int 65:116-128

40. Roh DD, Kamanna VS, Kirschenbaum MA (1998) Oxidative modification of low-density lipoprotein enhances mesangial cell protein synthesis and gene expression of extracellular matrix proteins. Am J Nephrol 18:344-350

41. Akiba S, Mukaida Y, Hane K et al (2006) Group IVA phospholipase A2-mediated production of fibronectin by oxidized LDL in mesangial cells. Kidney Int 70:1013-1018

42. Leung JC, Chan LY, Tsang AW et al (2004) Anti-macrophage migration inhibitory factor reduces transforming growth factor- $\beta 1$ expression in experimental IgA nephropathy. Nephrol Dial Transplant 19:1976-1985

43. Makino H, Sugiyama H, Kashihara N (2000) Apoptosis and extracellular matrix-cell interactions in kidney disease. Kidney Int 58:S67-S75

44. Artwohl M, Graier WF, Roden M et al (2003) Diabetic LDL triggers apoptosis in vascular endothelial cells. Diabetes 52:1240 1247

45. Marsche G, Zimmermann R, Horiuchi S, Tandon NN, Sattler W, Malle E (2003) Class B scavenger receptors CD36 and SR-BI are receptors for hypochlorite-modified low density lipoprotein. J Biol Chem 278:47562-47570

46. Grewal T, de Diego I, Kirchhoff MF et al (2003) High density lipoprotein-induced signaling of the MAPK pathway involves scavenger receptor type BI-mediated activation of Ras. J Biol Chem 278:16478-16481

47. Lin SJ, Shyue SK, Shih MC et al (2007) Superoxide dismutase and catalase inhibit oxidized low-density lipoprotein-induced human aortic smooth muscle cell proliferation: role of cell-cycle regulation, mitogen-activated protein kinases, and transcription factors. Atherosclerosis 190:124-134

48. Sun B, Nishihira J, Suzuki M et al (2003) Induction of macrophage migration inhibitory factor by lysophosphatidic acid: relevance to tumor growth and angiogenesis. Int $\mathrm{J}$ Mol Med 12:633-641 